\title{
RABELAIS Y ESPAÑA
}

\author{
Antonio Domínguez \\ Universidad de Zaragoza
}

\begin{abstract}
"Son espée ne feut valentienne, ny son poignart sarragossoys, car son père hayssoit tous ces indalgos bourrachous, marraniséz comme diables"
\end{abstract}

\section{INTRODUCCION}

François Rabelais, como ya se ha reiterado hasta la saciedad, es, de todos los grandes escritores con que cuenta la literatura universal el menos popular, el menos comprendido y estudiado, y, por ende, apreciado. Nuestro país, desgraciadamente, no quiso ser "diferente": muy por el contrario, la olímpica indiferencia con que la todopoderosa España de Lope y de Cervantes -aquel Imperio que con la espada en una mano y el crucifijo en la otra despreció cuanto ignoró- consideraba todo lo que se hacía o provenía de fuera, acentuó el desconocimiento de nuestro autor.

La primera traducción española de las obras completas de Rabelais data de 1924, efectuada por el abogado Barriobero Herrán, quien ya había sido también el primer español en traducir algo de la producción rabelesiana con su entrega a la imprenta, en 1905, del Gargantua, traducción iniciada - iserá una cruel paradoja?- en la cárcel. Hoy día son numerosas las editoriales que, en ediciones más o menos lujosas, más podadas que completas, peor que mejor traducidas, han dado a conocer a los lectores y estudiosos españoles la incontenible cascada de fantasía verbal que Rabelais diera a luz cuatro siglos antes.

1 Gargantua, cap. 8, pág. 50. Para esta y las restantes citas del texto rabelesiano, se ha utilizado la edición de sus Oeuvres Complètes, por J. Boulanger, revisada y completada por L. Scheler, en Bibliothèque de La Pléiade, Paris, ed. de 1955. 


\section{ANTONIO DOMINGUEZ}

Hoy día, sin embargo, todavía echamos de menos una auténtica edición y traducción de sus obras completas en los países de habla hispánica.

Súbdito de un país a la sazón enemigo de España, suele citarnos con gran frecuencia en su obra aunque, eso sí, con tonos despectivos, insultantes: ni tan siquiera esos aceros templados con tanto esmero en las armerías de Zaragoza o Valencia son dignos de calzar las vainas de los caballeros franceses; más, cuando se olvida de la guerra para ocuparse del amor hace que la lengua castellana figure en "les belles et grandes librairies" de la famosa abadía de Thélème, reconocerá que el solo hecho de ponerse una capa española no conferirá al galán la "fiereza" y el "coraje" del hombre español, etc...

Alabándonos unas veces y denostándonos otras, Rabelais viene a demostrar algo que nos interesa: que conoce las cosas de España y a los españoles. ¿Cómo llegó a este conocimiento? ¿Fue Rabelais conocido por nuestros antepasados? Unicamente un detalle anecdótico: había un español interesado, y mucho, por nuestro hombre. E1 23 de noviembre de 1563 el embajador de España en la corte francesa envió un memorandum a Madrid donde se criticaba la educación recibida por Carlos IX de Francia:

“On lui fait la lecture d'un livre de bouffonneries qu'on nomme Pantagruel, fait par un anabaptiste et plein de mille plaisanteries sur la religion"2.

Ignoramos el alcance que esta opinión pudo tener en el país vecino si llegó a su conocimiento pero sí somos conscientes de la influencia que debió ejercer sobre una Inquisición como la española, siempre dispuesta a sajar toda página, o a quemar el conjunto, a la más mínima sospecha.

Así pues, creemos que aquella indiferencia hacia lo foráneo más la rígida censura ejercida por la Inquisición sobre toda obra sospechosa de luteranismo, modernismo o "frivolidad", fueron las causas inmediatas y determinantes del desconocimiento de Rabelais y de la aparente escasa incidencia de su obra.

El presente trabajo, incompleto, ya que después de su entrega a la imprenta hemos tenido la oportunidad de descubrir nuevos datos, se ceñirá pues a la elaboración de un bosquejo sobre las supuestas influencias españolas en la obra de Rabelais y a la posible impronta que éste último pudiera haber ejercido sobre alguno de nuestros escritores. De pasada se alude a aspectos referidos al apasionante mundo de la difusión y problemas acarreados por los libros durante los siglos XVI. y XVII. Conscientemente hemos querido que este trabajo no superara los estrechos límites de una primera aproximación. 


\section{RABELAIS Y ESPAÑA}

\section{INQUISICION, LIBROS PROHIBIDOS Y SU DIFUSION}

Joseph Gillet ${ }^{3}$, autor del único trabajo, muy breve, sobre las relaciones entre Rabelais y España, sostiene que las obras de Maitre Alcofibras Nasier, hermoso seudónimo bajo el que nuestro autor ocultaba sus ironías y mordacidades, conocen su primera prohibición en los Indices Franceses de la Sorbona ${ }^{4}$ $y$ en el ordenado confeccionar por el gran inquisidor Vidal de Becanis en $1550^{5}$. El Indice de Lieja, de 1569, que prohibe todas las obras de "Franciscus Rabela. tius"6 no había penetrado en España, aunque si lo hubiera hecho el de Anvers, aparecido en 1570 , donde nuestro hombre también merece unas líneas. Según Gillet, fue a través de este último índice donde los inquisidores españoles conocieron el anatema que pesaba sobre las obras rabelesianas, al mismo tiempo que afirma que el primer índice español es el de Valdés, aparecido en 1559, en el que, al igual que el de Quiroga, de 1583, no aparece mención alguna sobre Rabelais. Termina señalando que nuestro autor, escritor en lengua vulgar, no suponía peligro alguno !para Espana, dadas las dificultades de comprensión que su difícil y rico vocabulario entrañaban.

Gillet, buen estudioso y conocedor de nuestra cultura, incurre en una serie de pequeñas inexactitudes: el primer índice español no fue el de Valdés, en 1559, sino el de Toledo, publicado en 1551, que además era una fiel reproducción del que un año antes había sido impreso en los Paises Bajos ${ }^{7}$, bajo el título de Cathalogus librorum prohibitorum et reprobatorum ex iudicio academiae Lovaniensis; éste mismo será el que, traducido, aparecerá en Valladolid en 1559, de la mano del arzobispo Valdés ${ }^{8}$.

Cuando se refiere a las obvias dificultades del vocabulario rabelesiano, Gillet olvida que el mismo problema se ofrecía a los lectores franceses pero sobre todo, deja de lado dos hechos: de una parte la exquisita calidad de los traductores españoles de la época, tremendamente duchos en lidiar obras de igual o mayor dificultad léxica, por lo que no les hubiera resultado muy difícil traducir a Rabelais: así, por ejemplo, Bernardo Pérez, quien en 1529 "avait traduit déjà la Déclaration del Pater Noster", o que "fit paraitre à Valence sa traduc-

Gillet, "Note sur Rabelais en Espagne", en la Revue de Littérature Comparée, 1936, págs. $140-44$.

4 Véase, Reusch, Die indices librorum prohibitorum sechzeutem Jahrhunderst. Tübingen, 1886, págs. 124 y ss.

5 Ibid., pág. 133.

6 Ibid., pág. 285

7 Les catalogues des livres reprouuez..., par l'Université de Louvain. Lovaina, 1550.

8 Véase, Tres Indices expurgatorios de la Inquisición española en el siglo XVI. Nuevamente a la luz reproducidos en facsímil por acuerdo de la Real Academia Española. Madrid, año de 1952. 


\section{ANTONIO DOMINGUEZ}

tion des Silènes d'Alcibiade"9 ; o Baltasar Pérez del Castillo, dedicado exclusivamente a traducir obras francesas en Sevilla, labor que continuará desde 1569 en Alcalá, autores como Simón Abril, Martín Jeso de Oropesa, Juan Martín Cordero, Juan Carrillo y Sotomayor, Alberto de Aguago, etc., que merced a sus profundos conocimientos del francés, de lo que hacen gala en numerosas traducciones, perfectamente hubieran podido acometer la tarea de traducir las obras de Rabelais; por otra parte, no son pocos los españoles que conocían el francés en los siglos XVI y XVII y que leían a los autores galos en versiones originales.

Y este conocimiento lingüístico del francés se hace evidente al observar las numerosas partidas de libros que, procedentes de Lyon, llegaban a nuestras ciudades. Eran numerosos los libreros franceses cuya fuente de pingües beneficios radicaba en el comercio clandestino de libros con España. Bástenos con citar aquí un ejemplo que nos interesa doblemente: entre los envíos de obras que -vía clandestinidad- llegaban a Valencia desde Lyon, en 1556, figuran, entre un numeroso elenco de títulos franceses de distintos autores, varias obras de Rabelais. Ello se puede comprobar leyendo el legajo instruido por la Santa Inquisición en el proceso incoado contra Jerónimo Conqués, acusado de herejía, y en el que se adjuntan como pruebas y testimonios delectivos la correspondencia mantenida por el acusado con Gaspar Centellas entre los años que van de 1554 a 1562 . En una de las cartas, de 1556, Conqués remite a su amigo una relación de libros que acaba de recibir de Lyon por medio del librero Contin; con especial interés aparece recomendado un libro:

"Pantagruel, libro francés con el qual creo que se olgará si allega en mi poder", 10

De esta cita puede desprenderse que Conqués, seguro conocedor del libro, tenia dificultades a la hora de conseguir el número de ejemplares suficientes para proveer a todos sus amigos.

La Inquisición actuaba pero en base a las prohibiciones de los índices foráneos, ya que deberemos esperar al siglo XVIII, en el año de gracia de 1790, para que las obras de Rabelais aparezcan formalmente incluidas en un Indice netamente español ${ }^{11}$. Tras recopilar las distintas prohibiciones de los índices del Vaticano, añade una serie de títulos que circulaban por nuestro país y se consideraba que eran merecedores de las más severas y duras prohibiciones. Anotaremos las siguientes menciones:

9 M. Bataillon, Erasme et l'Espagne, Ginebra, Droz, 1937, pág. 336. La traducción española, en FCE, 1950.

10 Véase en Archivo Histórico Nacional. Madrid, Sección de Inquisición (Valencia). Legajo 558, fo $75, \mathrm{r}^{\circ}$.

11 Indice último de los libros prohibidos y mandados expurgar para todos los reynos y señoríos del católico rey de las Españas, el señor don Carlos IV. Madrid, Imprenta del Sr. D. Antonio Sancha, MDCCXC. 


\section{RABELAIS Y ESPAÑA}

- Rabelais, François. Escribió en francés, son: Gargantua,

- Item, Pantagruel. Item, Mensonjes de son Pantagruel. Obras prohibidas.

- Rabelaesus, Francisc. I. cl.

- Rabletius, Francisco. I. cl.

y a pie de página, en la 237 , aparece una advertencia:

"en el artículo Rabelais, François, hay tres obras: entiéndase estar todas tres prohibidas".

Nos conviene señalar que la prohibición no es total en este índice, ya que mediante la correspondiente licencia era dado leer las obras.

De todos los datos hasta ahora apuntados, y antes de pasar a estudiar las posibles relaciones entre Rabelais y España, nos interesa resaltar que la primera prohibición de leer a nuestro autor en España - prohibición parcial, ya que con permiso se podía leerlo-, claramente explicitada y con mención de las obras, es de las postrimerías del siglo XVIII; nos interesa señalar que las supuestas dificultades léxicas no eran tales, como muestra el hecho de la difusión y lectura de las obras de nuestro autor, en francés, y que, cuando estas obras aparecen incluidas en un índice español, debe explicitarse con tres menciones al nombre de Rabelais, la última de ellas españolizada.

Si la obra de Rabelais no fue traducida al castellano, si no tuvo una enorexpansión, no por ello tropezó con la indiferencia: muchos españoles gozaron de su sustancia y por ello alguno consumió la suya en la hoguera.

\section{INFLUENCIAS ESPAÑOLAS EN LA OBRA DE RABELAIS}

Este es un terreno virgen y repleto de numerosas dificultades, todavía por desbrozar, pues apenas se ha escrito sobre las posibles influencias hispanas en la obra de Rabelais. Menéndez Pelayo, en el primer volumen de sus Origenes de la novela, piensa que tanto el arcipreste de Talavera como anteriormente el de Hita podrian ser considerados como lejanos precedentes de Rabelais; socorriendo su hipótesis, el insigne polígrafo acude a las opiniones del conde de Puymaigre ${ }^{12}$, quien en su estudio de las relaciones existentes entre la Reprobación del Amor Mundano y La Tragicomedia de Calix to y Melibea dice que en algunos momentos las enumeraciones sonoras y pintorescas del Corvacho, tan intempestivas como las de Rabelais, aparecen igualmente en la Celestina ${ }^{13}$. Igualmente pasa con Tirant lo Blanch, según Menéndez Pelayo, que dirấ "nos ha faltado ver que algún

12 C. de Puymaigre, La Cour Littéraire de Don Juan II. París, 1873, 2 vols.

13 Menéndez y Pelayo, Origenes de la Novela, vol. I, V, pág. 399 y ss. Madrid, C.S.I.C., 1943. 


\section{ANTONIO DOMINGUEZ}

excelente crítico consideró el Tirante como una parodia deliberada de los libros de caballerias, que, en todo caso, (pensamos), seria más parecida a la de Coccaio o a la de Rabelais que a la de la fina ironía del Ariosto o a la grande y humana sátira del insigne Cervantes" 14 .

Nos parece muy arriesgado conjeturar sobre este tipo de comparaciones; en el caso del Tirant podría establecerse algún paralelismo pero más desde una perspectiva temática que formal, y sin olvidar que esta obra se inscribe en el ámbito de una cultura, la catalana, que por su entronque con las lenguas de "oc" podía resultarle más familiar a Rabelais, quien a lo largo y ancho de su obra aludirá a una serie de libros místicos traducidos al catalán o a la lengua de oc (por ej., Le Creziou de Contemplation, etc... ${ }^{15}$ ). Ciertamente, y ya lo señaló Pelayo, algunos episodios del Tirant son tan desenfadados y mordaces como los desarrollados en Gargantua o Pantagruel: por ejemplo, aquel donde se produce el desafío entre Tirante y el caballero francés Villermes, los dos en paños menores, defendiéndose con escudos de papel y coronados con sendas guirnaldas de flores a modo de cascos, o aquel otro en que una sarta de bufonadas aparecen incrustadas en los rezos de la emperatriz, e incluso aquellos en los que se manifiesta un sensual regocijo, tan grosero, por lo menos, como los mejores pasajes escatológicos de Rabelais.

En esta línea de posibles pero no confirmadas relaciones, Leo Spitzer ${ }^{16}$ pensó en la existencia de un cierto paralelismo entre la obra del arcipreste de Hita y Rabelais al considerar que ambos son engarces de una cadena caracterizada por una santa borrachera de la vida por la vida.

Celestina, ese "aberrante mensajero de desdichas", esa "vieja de cháchara intencionada", etc., ha sido considerada, en cierto modo, como un antepasado del astuto y taimado Panurgo pero sin olvidar que estos personajes pertenecen a una tradición literaria anterior que se prolongará hasta muy entrado el siglo XVII.

$\mathrm{Si}$ lo anteriormente expuesto se reduce a conjeturar meras suposiciones, no ocurre lo mismo con la impronta que sobre una de las facetas más interesantes de la obra rabelesiana, la pedagogía, ejerció uno de nuestros más afamados "heterodoxos": Luis Vives; y además una impronta destacable: la celebérrima carta que papá Gargantua escribe a su siempre bien amado hijo está directamente inspirada del De Tradentis disciplinis de Vives, que había sido publicado en 1531, mientras que Pantagruel aparece en 1532. Además, G.-L. Michaud ${ }^{17}$ puso de relieve el hecho de que Hilaire Bertholf, condiscípulo y amigo de Vives,

14 ibid., pág. 400.

15 Véase, P. Lacroix, Catalogue de la Bibliothèque de L'Abbaye de Saint-Victor au seizième siècle. Rédigée par F. Rabelais. Paris, J. Techener, 1861. Especialmente nos interesan las págs. 79 y siguientes.

16 L. Spitzer, Sur Rabelais. Lit. Pieces of the Western World. J. Hophms Press, 1953. En la pág. 149 trata los aspectos a que aludimos.

17 Michaud, "L'Influence de Vivès sur Rabelais", en la Revue du Seizième siècle, XII, 


\section{RABELAIS Y ESPAÑA}

era uno de los más intimos amigos lioneses de Rabelais allá por 1532 y que, a través de este amigo común, Rabelais conoció el contenido de muchos de los aspectos del Tradentis con anterioridad a la publicación del Pantagruel. Las ideas pedagógicas que Vives puso en voga suponían una auténtica revolución de los cánones educativos existentes en el siglo XVI: eran una protesta contra el aristotelismo y el autoritarismo, eran una creencia y afirmación de la necesidad del ejercicio del juicio individual como instrumento para el conocimiento de la verdad y como proceso del desenvolvimiento educativo en el individuo, sostenían que la verdad está abierta a todo el mundo, considerando $-y$ en esto se adelantaba a Rousseau-- que la naturaleza es el mejor libro didáctico y que nuestros primeros maestros son los sentidos, recomendando el destierro del latín corrompido, dando gran importancia al estudio de las lenguas vulgares y de la historia moderna, estaba de acuerdo en que los juegos se practicaran en la escuela, a condición de que fuesen serios, decentes, alegres y contribuyeran al desarrollo del cuerpo. En definitiva, la pedagogía de Vives podría resumirse como un intento para desarrollar el armónico conjunto de la personalidad humana y su formación integral.

Unicamente para comprobar esta influencia, y sin ánimos de exhaustividad, vamos a efectuar un cotejo de los capítulos XXI al XXIV del Gargantua, VI y VIII del Pantagruel y el XLVIII del Tiers livre, con la obra de Vives.

Los párrafos e ideas concordantes son muy significativos: "Ce faict, voulut de tout son sens estudier à la discrétion de Ponocrates"18; "et là passoient toute la journée à faire la plus grande chère dont ilz se pouvoient adviser, raillans, gaudissans, jouans, chantans, dansans, se voytrans en quelque beau pré, denichans des passereaulx, prenans des cailles, peschans aux grenouilles et escrevisses 19 ; "Quand Ponocrates congneut la vitieuse manière de vivre de Gargantua, délibéra aultrement le instituer en lettres, mais pour les premiers jours le toléra, considérant que Nature ne endure mutations suobdaines sans grande violence $^{20} "$; el capítulo VI del Pantagruel será una apasionada defensa de la lengua vulgar, opuesta a ese latín degenerado que el estudiante lemosí se jacta de perorar y que, fuerza obliga, olvidará, para hablar en francés, cuando Pantagruel le obligue a ello asiéndole fuertemente por el cuello y diciéndole "à ceste heure parles-tu naturellement".

Pero el capítulo estimado unánimente por todos los estudiosos como el más significativo de la pedagogía rabelesiana es el VIII de Pantagruel $^{21}$, marco

1925, págs. 148-155; véase también J. Larmat, Le moyen âge dans Gargantua. Paris, 1972, págs. 325-327.

18 Gargantua, pág. 84.

19 Ibid., pág. 90.

20 Ibid., pág. 90.

21 "Comment Pantagruel estant à Paris, receut lettres de son père Gargantua, et la copie d'icelles". 


\section{ANTONIO DOMINGUEZ}

donde se inscribre la famosa y paternal carta que Gargantua envía a su "trèz chier filz". Pues bien, esta misiva está profundamente inspirada en la obra de Vives; aunque algún aspecto fue puesto de relieve por Larmat, en la obra ya citada, no resistimos la tentación de transcribir algunos ejemplos:

Vives - Studium Graecitatis Quintalianus jubet Latinis litteris praeponi... (303)

Gargantua - J'entens et veulx que tu aprenes les langues parfaictement. Premièrement la grecque, comme le veult Quintilian (p. 227)

Vives - Quodcirca vehementer cuperem... ( )... non solum illarum (latín, griego y hebreo), sed Arabicae, sed aerum etiam quae essent Agarenis populis vernaculae (p. 300)

Gargantua - ... secondement, la latine, et puis l'hébraicque pour les sainctes lettres, et la chaldaïcque et arabicque pareillement (p. 227)

Vives - Ástronomica (...) non referetur ad divinationem venturarum vel abditarum rerum, quae ingenti vanitate humanos animos detinet (p. 371)

Gargantua - Des ars libéraux...; poursuys la reste, et de astronomie saicheen tous les canons; laisse-moy L'astrologie divinatrice et l'art de Lullius, comme abuz et vanitéz (p. 227)

El capítulo XLVIII del Tiers livre ${ }^{22}$ recoge una serie de recomendaciones morales acerca de las relaciones paterno-filiales, destacando la admonición a la que Pantagruel responderá así:

“Je n'ay jamais entendu que, par loy aulcune, feust sacré, feust prophane et barbare, ayt esté en arbitre des enfans soy marier, non consentans, voulens et promovens leurs pères, mères et parens prochains. Tous législateurs ont ès enfans ceste liberté tollue, ès parens l'ont réservée"23.

Gargantua, satisfecho, visiblemente satisfecho por la muy sesuda argumentación de su hijo, le responderá con estas palabras:

“... Car (comme très bien l'avez dict) loy on monde n'estoit qui ès enfans liberté de soy marier donnast sans le sceu, l'adveu et consentement de leurs pères" 24 .

Exactamente las mismas ideas que Vives reitera en todos sus trabajos e incluso cuando no viene al caso. Es inflexible en un precepto inexorable: "No

22 "Comment Gargantua demonstre n'estre licite ès enfans soy marier sans le sceu et adveu de leurs pères et mères".

23 Tiers livre, p. 518.

24 Ibid., p. 518. 


\section{RABELAIS Y ESPAÑNA}

es ella (o él) quien debe buscar a su marido (o a su esposa); este asunto es de la incumbencia exclusiva de los padres".

Esta escasa relación de citas, que como hemos señalado dista mucho de ser exhaustiva, y que en un análisis más profundo de las respectivas obras de Vives y Rabelais mostraría feacientemente de qué manera la pedagogía del español impregnó el conjunto de ideas que Rabelais pone en boca de sus héroes, siendo además esta influencia la razón del un tanto sorprendente tránsito rabelesiano de la educación medieval y sofista -representada por Maitre Thubal Holofornea la más moderna y refinada del Renacimiento - representada por Ponocrates-, nos parece suficiente para los objetivos del trabajo.

En un trabajo como el que nos ocupa, limitado por el número de páginas, sería ocioso traer a colación las numerosas citas que tienen como protagonista a España, los españoles o aspectos relacionados con ellos en la obra de Rabelais. En todo caso, supone todo ello una serie de lecturas y conocimientos sobre nosotros, realmente gratificador. De todos modos, y como único dato que aquí daremos, vamos a detenernos unos momentos, los suficientes para el reposo, en la alquería de la abadia de San Víctor. Allí, de milagro no, nos hemos encontrado con el célebre catálogo de la librería que lleva el mismo nombre, y, entre los títulos reseñados, aparece el siguiente: Le Faguenat des Hespaignolz, supercoquelicanticqué, par Frai Iñigo ${ }^{25}$. Una traducción aproximada del mismo al castellano podría ser El mal olor de los españoles, superquiquiriquiestructuralizadamente evidenciado por Fray Iñigo (lógicamente, de Loyola). Estamos ante un título inventado de una obra no menos imaginaria, con un autor -supuesto- de carne y hueso, pero que nos sugiere algunas elucubraciones - piensen ustedes-, más o menos desbaratadas. La palabra "faguenat" es de cosecha rabelesiana y ha recibido muchas y distintas interpretaciones; ¿podría referirse a la palabra española "faja"? En todo caso connota ese fétido olor producido por los excrementos calientes, y la real mención del nombre de quien aparece como supuesto autor, Fra Iñigo, nos podria permitir suponer que Rabelais pretendía con este juego ridiculizar al fundador de la Compañia de Jesús, obligado por las circunstancias de la vida, a la sazón, a vivir como un bohemio por ese Paris montmartriano de cuyos cabarets era un excelente introductor y embajador Rabelais. $\mathrm{Y}$ piénsese, además, que como $\mathrm{Jacob}_{\text {apuntaba }}{ }^{26}$, la palabra "faguenat" podía ser al mismo tiempo un hermoso juego: ¿no será el resultado de abreviar y posteriormente fundir los nombres de Ignatius (de Loyola) y Faber (Pedro) -este último maestro del anterior en el colegio de Sainte-Barbe-, en un momento en que Ignacio ya se dedica a elaborar sus famosos Ejercicios Espirituales? Nosotros queremos insistir, aunque pueda estimarse que lo es en

26 También alude nuestro autor a otras obras de autores hispanos, como el De Bastifolaghs Principium de R. Lulio, l'Accoudouere de Vieillesse, que es una traducción francesa del Regimen Sanitatis de A. de Villanova ( $₫$ Miguel Servet?), etc... Todo ello, evidentemente, mezclando realidad y ficción. 


\section{ANTONIO DOMINGUEZ}

el terreno de la mera especulación, en la idea de que Rabelais haya podido toparse en Paris con Ignacio de Loyola, famoso en esa época por su miseria y suciedad, cuando callejeaba mendigando en compañía de sus discípulos y primeros apóstoles Laínez, Salmerón, Bobadilla y Simón Rodriguez; y queremos insistir en esa idea porque no debemos olvidar que Loyola había estudiado también gramática, en el colegio de Montaigu, esactamente en 1528, colegio de renombre pero sobre todo famoso por la suciedad y falta de higiene de sus alumnos, a quienes el propio Rabelais compara en su obra con los "guenaulx de Sainct Innocent", otorgando al colegio el lustroso título de "Colliège de pouillerie"27 28 . Si este juego nos permite relacionar a ambos genios, nos permite hablar de un conocimiento directo, es evidente que en ningún caso podría dar pie a suponer influencia de tipo alguno ignaciana en las obras de nuestro autor.

Esta pequeña panorámica que hemos esbozado nos viene a decir y concluir que por el momento cualquier intento de cara a establecer relaciones en las que se patentice la influencia española sobre la obra de Rabelais carece de sólidos cimientos, si exceptuamos el caso de Vives. Mejor será concluir que Rabelais es un autor inscrito en la tradicción medieval del mundo al revés, en esa tradición que ha bebido en las fuentes latinas -especialmente en Luciano-, en esos senos que han alimentado a toda una extensa nómina de obras literarias europeas y que por ello ofrecen ciertas similitudes, y que van desde Los Amores de Calixto y Melibea y El Corvacho hasta los Sueños de Quevedo, pasando por Los Viajes de Gulliver, el Elogio de la Locura, el Cimbalum mundi, el Crotalón, la Sátira Menipea, el Coloquio de los Perros, etc...

\section{INFLUENCIA DE RABELAIS EN LA LITERATURA ESPAÑOLA}

Los límites de trabajo nos impiden dedicar la atención requerida a esa poliédrica gama de matices que se vienen considerando imprescindibles para abordar los problemas planteados por la literatura comparada. Los manuales de literatura española apenas recuerdan que existió un tal Rabelais y cuando lo mientan es para liquidarlo con una breve alusión, las más de las veces incoherente o parcial. Unicamente Valbuena Prat ${ }^{29}$ le ha dedicado ocho páginas de atención, apuntando la posible relación entre nuestro autor y su coetáneo Guevara; Alborg, en su historia de la literatura española lo cita una sola vez; los manuales

y estudios de los investigadores franceses han eludido casi siempre el compromiso de estudiar - en la medida que ello es posible-, la obra de Maitre François en sus relaciones -o incidencias-con España ${ }^{30}$. De ahí que nuestra apor-

27 Gargantua, cap. 37, pág. 131.

28 Véase $o p$. cit., en nota 15 , especialmente págs. 79 y ss.

29 V. Prat, Literatura española en sus relaciones con la universal. Madrid, SAETA, 1965, pág. 222-228.

30 No existe trabajo alguno sobre este tema en España; en Francia, aparte de los parciales, 


\section{RABELAIS Y ESPAÑA}

tación debe considerarse como una radiografía de urgencia, que sitúa aspectos a desarrollar con mayor profundidad en otra ocasión.

\section{Cristobal de Villalón}

Marcel Bataillon, en la página 734 de su magno trabajo Erasme et l'Espagne, hace la siguiente alusión:

"Dans la galérie de l'érasmisme espagnol, le docteur Laguna, philologue, homme de science, praticien, voyageur, tient une place comparable à celle qu'occupe dans l'humanisme françois son contrère Kabelais, qu'il a peut-être connu à Rome (1543) et don il a sûrement aimé le PANTAGRUEL. Il s'apparente à lui par l'ouverture d'esprit par l'aisance à intégrer une riche culture dans les savoureuses coutumes et histoires du folklore national. Mais le Rabelais castillan est, comme il se doit, plus sobre, moins débrillé, plus austère..."

Merece la pena traer aquí esta larga referencia; este singular Rabelais castellano parece ser la misma persona que Cristobal de Villalón, autor del célebre Viaje a Turquia, obra en la que aparecen algunos puntos de contacto con la producción rabelesiana: en la redacción del manuscrito n. ${ }^{\circ} 387$ de la Biblioteca Nacional de Madrid los personajes del Viaje, que en la redacción del manuscrito n. 529 se llaman Juan de Votadios, Mátalascallando y Pedro de Urdemala, aparecen --únicamente en el primer coloquio-bajo los nombres de Apatilo, Polítropo y el tercero de ellos PANURGO. Estamos pues ante un personaje de una obra literaria española que lleva el nombre de uno de los más famosos héroes rabelesianos.

Si nos detenemos en ver la estructuración de este primer coloquio observaremos que, más o menos, es así: "Salen de paseo Apatilo y Panurgo por el Camino Real o francés de Valladolid. - Inventivas contra los peregrinos y mendigos que por allí pasaban.- Encuentro de Patilo y Panurgo con un fraile extranjero.- Conversación con éste.- El fraile habla en mil y una lenguas extrañas.- Descubre ser su amigo Polítropo o Pedro de Urdemala (Cristóbal de Villalón) y promete referirles sus aventuras.

Este fraile extranjero habla una serie de lenguas desconocidas para sus interlocutores $^{31}$ y comenzará a contarles las hazañas que llevó a cabo en Turquía y las artimañas a las que tuvo que recurrir para fugarse, además de los curiosos eventos que le acontecieron en su viaje de regreso.

y ya citados de Gillet y Michaut, y de los que se citan posteriormente, de Hatzfeld y Flecniakoska, también parciales, nada más. La obra de Boulanger, Rabelais à travers les âges, Paris, Le Divan, 1923, se limita a indicarnos que en España funciona un club de gastrónomos llamado Rabelais.

31 C. de Villalón, Viaje a Turquía, N.B.A.E., T. II, 1905, edición de Serrano y Sanz. Serrano hace una mención en la que dice que acaso Villalón conoció la obra de Rabelais. 


\section{ANTONIO DOMINGUEZ}

Rabelais, en el capítulo IX del Pantagruel $^{32}$ nos relatará el encuentro de éste con Panurgo, a quién querrá desde entonces para toda la vida; la estructura del capítulo es como sigue: Pantagruel sale de paseo con sus amigos por el camino de Charenton.- Habla de un hombre que por allí pasaba.- Se encuentra con Panurgo.- Conversación con éste.- Panurgo habla en una y mil lenguas extrañas.- Les descubre quien es.

También las lenguas empleadas por Panurgo son desconocidas por sus interlocutores y futuros amigos para toda la vida; iniciará la conversación relatándoles que viene de Turquía, así como las artimañas y tretas utilizadas para escapar de su prisión. En capítulos posteriores contará los hechos y anécdotas acontecidas en su viaje de vuelta. Curiosamente, una de las lenguas que utiliza es el español:

"Seignor, de tanto hablat yo soy cansado. Porque suplico a Vuestra Reverencia que mire a los preceptos evangélicos, para que ellos movant Vostra Reverencia a lo que es de conciencia; y si ellos no bastarent para mover Vuestra Reverencia a piedad, yo suplico que mire a la piedad natural, la qual yo creo que le movra como es de razón, y con esto no digo más"33

Es evidente que, además del nombre de Panurgo, $-\mathrm{y}$ dejando de lado el texto rabelesiano en castellano-, Villalón ha tomado del Pantagruel, modificándolo, este episodio; también el crítico y abierto espíritu que desparramó a todo lo largo y ancho de su obra. Si Cristóbal de Villalón es el enigmático y controvertido doctor Laguna, es muy posible que haya coincidio con Rabelais en Roma, en 1548, cuando este hacía de secretario del cardenal Du Bellay, tío del poeta renacentista del mismo nombre, y fue allí donde trabó conocimiento con la fantasía y acidez rabelesiana.

\section{Entremeses}

En los albores del siglo XVII apareció un curioso entremés, El Platillo, del que es autor Simón Aguado. Todo él está inscrito en ese desenfadado tono rabelesiano, repleto de despropósitos; pero además trata uno de los motivos menos utilizados en la literatura española de la época: el de frêre Jean cargando a sus espaldas el caballo, dándonos así un ejemplo del mundo al revés: " $\mathrm{y}$ el caballo de lonjinos encima de preste Juan" ${ }^{34}$.

En el entremés de la "Burla del Ropero"35, Ortuño naufraga y viene a

32 "Comment P. trouva Panurge, lequel il ayma toute sa vie".

33 Pantagruel, pág. 232. Igualmente lanza una perorata en euskera, lengua que utiliza en otros lugares de la obra "lagona edatera", etc...

34 Véase en Revista de Archivos, Bibliotecas y Museos, 1903, T. VIII, pág. 499.

35 "Entremés de la burla del ropero", en Rasgos del Ocio..., Madrid, 1661, paǵ. 121. 


\section{RABELAIS Y ESPAÑA}

dar con sus huesos en un país de gigantes: acosado, se oculta en un nada pequeño racimo de uvas y hete aquí que:

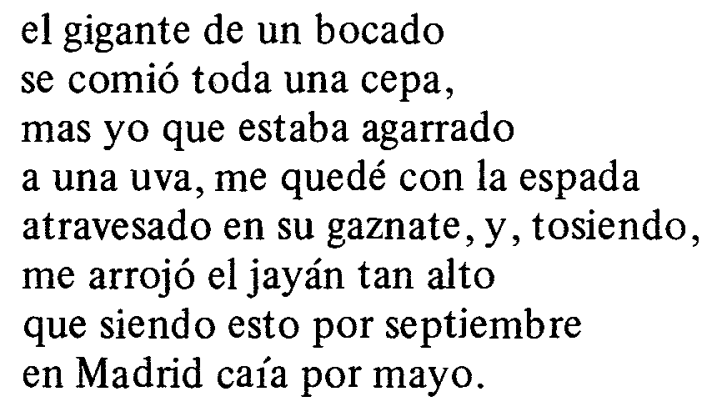

Este episodio evoca uno de los motivos más queridos por Rabelais y la literatura popular del siglo XVI francés: son innumerables las crónicas gragantuinas que hacen de él un condimento indispensable para el juego de la risa. Ásí, Rabelais le dedica un capítulo entero en su Gargantua ${ }^{36}$, donde nuestro héroe se comerá a unos peregrinos ocultos entre los tallos de guisantes, las coles y las lechugas. También intervendrá un milagroso bordón y los peregrinos englutidos serán violentamente expulsados de la boca del gigante. Esa desmesura temporal, marcada por la relación septiembre/mayo, es también muy usual como elemento cómico de la desmesura, en toda la creación rabelesiana.

Más adelante, nuestro intrépido Ortuño, que con la justicia había topado, va a hilvanar una retahila de justificaciones:
¿No has visto uno, que jugando a la argolla tira un cabo con tal destreza, que dando a la otra bola, la arroja, y ella su sitio ocupando se quedó alli? Pues así le arroja- ron de un balazo a un capitán su cabeza, y me dió tan gran porrazo que, arrojándome la mía, la del otro es la que traigo.

Idéntico tema, con escasas variantes, relata Panurgo en el capítulo XXX de Pantagruel $^{37}$; este mismo tratamiento del motivo aparece en obras de otros autores españoles, incluido el mismo Cervantes.

\section{La novela picaresca}

Campo fértil y abonado para lo atrevido y real de la época, la novela picaresca será uno de los marcos ideales para efectuar esa sátira social, humana y

36 Garg., cap. 38: "Comment Gargan tua mangea en sallade six pélérins".

37 Pant., cap. 37: "Comment Epistémon, qui avait la couppe testée, feut guéry habillement par Panurge, et des nouvelles des diables et des damnéz". 


\section{ANTONIO DOMINGUEZ}

tremendamente vitalista que Rabelais nos presenta en sus obras. La simpatía, el odio, la amargura, la compasión y la alegría de vivir, el humor desenfadado, el protagonismo del pueblo, serán las notas esenciales de las obras agrupadas bajo la denominación de novela picaresca.

En la Vida y hechos de Estebanillo González ${ }^{38}$ encontramos el episodio anteriormente tratado: un soldado le cuenta a Estebanillo la singular aventura que le ocurrió en Flandes, aventura similar a la ya citada del capítulo XXX de Pantagruel: Panurgo, hábil cirujano, colocará la cabeza de su amigo Epistemón en su propio tronco:

"après les oignit de je ne sçay quel oignement, et les afusta justement. veine contre veine, nerf contre nerf, spondyle contra spondyle, affin qu'il ne feust tortycolly"39.

Idéntico motivo aparece también en el entremés "Las noches del invierno y perdone el enfermo"40, aunque en esta ocasión será un soldado quien escuche de un tal Don Juan lo que le aconteció en Flandes; el soldado, típico ejemplo del clásico "fanfarrón", no se quedará a la zaga y endilgará a su interlocutor una explicación, si cabe, más fantástica: él mismo fue testigo del evento y puede jurar que fueron dos los cuerpos descabezados, cuerpos que mutuamente se trastocaron las cabezas ${ }^{41}$.

También tiene relación con estos episodios la explicación que Don Quijote dará a Sancho acerca de las virtudes curativas del bálsamo de Fierabrás:

"Es un bálsamo (...), cuando vieres que en alguna batalla me han partido por medio el cuerpo (como muchas veces suele acontecer), bonitamente la parte del cuerpo que hubiere caído en el suelo, y con mucha sotileza, antes que la sangre se hiele, la pondrás sobre la otra mitad, que quedará en la silla, advirtiendo de encajallo igualmente y al justo. Luego me darás a beber sólo dos tragos del bálsamo que he dicho, $\mathrm{y}$ verasme quedar más sano que una manzana"42.

Panurgo también insitirá en que su compañero aún está "tout chault", y cuando ha realizado la operación "luy fist à l'entour un peu d'un unguent qu'il appelloit resuscitatif", haciéndole beber acto seguido "un voirre d'un grand villain vin blanc".

39 Pantagruel, cap. XXX, págs. 316-18.

40 En Rasgos del Ocio..., Madrid, 1661, pág. 93.

41 Ibid., pág. 93.

42 Don Quijote, ed. Petronio, 1973, T. I., pág. 78.

43 Pantagruel, cap. XXX, pág. 317-18. 


\section{RABELAIS Y ESPAÑA}

En el Guzman de Alfarache, de Mateo Alemán, podemos rastrear pequeñas reminiscencias, apenas imperceptibles, casi apagadas, que podrían hacernos pensar que el autor español había leído a Rabelais. Cuando M. Alemán se disponía a redactar la segunda parte de su obra, un avispado individuo, oculto por el seudónimo de Mateo Lujan de Sayavedra, imprimió en Valencia o en Barcelona $^{44}$ un remedo que pretendía pasar por la segunda parte de la novela de Mateo Alemán ${ }^{45}$; en este Guzmán apócrifo, Juan Martí de Barcelona emprende un viaje a Italia, y al encontrarse en la más desesperada de las miserias, desamparado, practicará muchas de las 63 distintas técnicas utilizadas por el bueno de Panurgo para aligerar de peso a sus congéneres cuando la necesidad o el simple divertimento le impelían a practicar la caridad ajena.

El mismo Mateo Alemán otorgará a su héroe la capacidad de practicar las mismas técnicas en la segunda parte del Guzmán, tanto en el prólogo como en el capítulo IV del libro $1 .^{\circ}$ :

"Ninguno entendió como yo la cicatería: fui muy gentil caleta, buzo, cuatrero, maleador y mareador, pala, polea, escolta, estafa y zorro"

y en el capítulo IV del libro 2. ${ }^{\circ}$ :

"y hasta agora sé diez y siete maneras de pedir limosna"

En todo caso esto no pasa de la mera anécdota y sin importancia. Donde mayor similitud podríamos encontrar entre Rabelais y Mateo Alemán es en el tratamiento que ambos efectúan de la mujer: ambos dos son tremendamente remisos a conceder al amor ni el más pequeño viso de espiritualismo; los dos son misóginos militantes: cuando se refieren a la hembra, que no mujer, $-y$ en las contadas ocasiones en que lo hacen-, es para hacer de ellas el instrumento del en absoluto desdeñable amor carnal, el complemento indispensable para que aparezca "la bête à deux épaules". Este es un campo de trabajo aún en esbozo pero muy sugerente y atractivo.

\section{Miguel de Cervantes}

E1 insigne manco es, sin paliativos, el autor español que más se ha querido ver como próximo -dentro de lo que cabe-, a Rabelais. Podríamos aportar gran número de citas para avalar este aserto pero, lamentablemente, esta inconmesurable, exhaustiva relación de referencias, son veladas y veloces en muchos casos y enormes despropósitos en otros, careciendo las más de las veces de

44 No queremos entrar en la polémica existente en torno al lugar de edición de esta obra. Escapa al ámbito de nuestro trabajo y por ello nada decimos.

45 Véase Groussac, Un énigme littéraire. Le Don Quichotte de Avellaneda. Paris, Picard, 1903, págs. 171-2. 


\section{ANTONIO DOMINGUEZ.}

una base sólida. Nos ocuparesmo de algunas: Elie Faure ${ }^{46}$, que comienza considerando la segunda parte del Quijote como el resultado de la influencia ejercida por Montaigne sobre Cervantes, establecerá la relación entre Rabelais y nuestro insigne autor en base a ver en Sancho Panza nada menos que al ¡Panurgo español!;la autora E. O'Kane ${ }^{47}$ relacionará a ambos autores al considerarlos como incursos en una amplia tradición popular, deduciendo de ello la posibilidad de que hubieran podido conocer sus respectivas obras; Paul Groussac ${ }^{48}$ no tiene el menor recato en señalar, al hablar de Cervantes, que "son jugement sur les passages, les présages, la beauté et l'amour qui pourrait être de Montaigne; comme tel autre, sur la poésie, pourrait être d'un Rabelais abstème et nullement envrivré du vin pur de la Gréce et de la Renaissance"; Paz de Borbón ${ }^{49}$ comparará a ambos escritores tomando como referencia una cierta afinidad o analogía misteriosa entre las cualidades de Don Quijote y los rasgos específicos del espíritu francés. Y en esta misma línea se inscriben la mayor parte de las alusiones.

Mención aparte merece, sin embargo, por la seriedad y rigor con que ha sido emitido, el juicio comparativo de Helmuldt Hatzfeld ${ }^{50}$, que comienza reconociendo el hecho de que "no existe dependencia material e histórica del autor español respecto del autor francés", para considerar que Cervantes ha sido el creador de la novela moderna "en un sentido totalmente distinto que Rabelais". Partiendo de un supuesto bastante aceptado, considera que la sátira ejercida por ambos maestros se ha nutrido en las fuentes italianas, aunque posteriormente se manifestaron en direcciones "distintas" y "no coincidentes".

Sentados estos supuestos evidenciará la relación que, al menos en dos niveles, puede intentar establecerse entre ambos autores: por una parte en el nivel de la "verbosidad"\$1, y por otra en la "visión del humor y el sentido de la realidad de ambos". Para mayores detalles remitimos al artículo de Hatzfeld, no sin antes apuntar la imposibilidad de aventurarnos a afirmar que Cervantes hubiera podido conocer la obra de Rabelais ni que le hubiera servido de fuente inspiratriz, aunque si podría caber la posibilidad de que hubiera llegado a tener noticias de su obra a través de Italia, como ya había apuntado Gillet:

"Malgré l'Inquisition, le nom de Rabelais eût pu se révèler à la curiosité du grand espagnol par la traduction de certaines oeuvres qui mentionnent l'auteur français, par exemple celles des Relazioni Universali, de

46 E. Faure.-Montaigne et ses trois premiers-nés. Paris, Cres, 1926.

47 O'Kane.- "The proverbs: Rabelais and Cervantes", en Comparative Literature, II, 1950, pág. 360-69.

48 Groussac, op. cit., pág. 80.

49 Paz de Borbón, Buscando las huellas de Don Quijote. Friburgo, 1905, pág. 63.

50 Hatzfled. "Puntos de contacto artísticos entre Cervantes y Rabelais", en Bol. de la Biblioteca Menéndez y Pelayo, IX, 1927, pág. 210-227.

51 Mejor que el término "verbosidad" sería utilizar el acuñado por Garapon, de "fantasía verbal", hoy unánimemente aceptado. 


\section{RABELAIS Y ESPAÑA}

Giovanni Botero, publiées en 1595 et bientôt traduites par Diego de Aguiar"s2.

Un rastreo de las obras de ambos autores nos muestra la existencia en ellas de citas y nombres de personajes comunes: nombres de gigantes, de seres fantásticos, el tratamiento de los libros y bibliotecas, aunque con diferentes finalidades. Pero no creemos, como sostiene Flecniakoska ${ }^{53}$, que se deba a otra causa que a una fuente originaria que utiliza temas tradicionales muy usuales en la literatura y el folklore de los distintos pueblos europeos, como podría mostrar un estudio de los temas de los cuentos y fabliaux franceses que aparecen en los entremeses españoles del siglo XVII. En el caso de las célebres operaciones de trasplantes de cabezas, Flecniakoska sostiene que los autores españoles que tratan el tema no han leído a Rabelais, y que, más bien, una broma de estudiantes de medicina, que se ha propagado de facultad en facultad para después ser tomada como hecho real y, colportada, transformada y adaptada por los autores de entremeses de los distintos paises, es la causa de estos fenómenos comunes.

\section{Francisco de Quevedo}

En una situación como la que venimos exponiendo, el hecho de que a comienzos del siglo XVII se produzca un ataque contra Rabelais en España, tiene un interés extraordinario ${ }^{54}$.

Aparece en un opúsculo que fue utilizado por una extensa relación de eruditos para sostener que el autor del falso Quijote, Avellaneda, no era otro que Fray Luis de Aliaga, confesor del rey. Este opúsculo, cuya finalidad consistia en atacar duramente a Quevedo ${ }^{55}$, apareció en Huesca, en 1626 , en diez hojitas, bajo el siguiente título: Venganza de la lengua española contra el autor del Cuento de Cuentos, por don Juan Alonso Laureles, cavallero de hávito y Peón de muchas costumbres, Aragonés liso y Castellano revuelto ${ }^{56}$. Aunque ya Gillet hiciese mención del mismo, no nos resistimos, por su interés, a citar el primer texto conocido en donde se formula una opinión, más o menos extensa, sobre Rabelais, en nuestro país:

"Rey era Francisco $\mathrm{I}^{\mathrm{O}}$ quando un hombre de baxo quilate, de menguada suerte, así en los bienes de la naturaleza como de la fortuna, lla-

52 Gillet, op. cit., pág. 142-3.

53 "Les "têtes coupées" en Espagne et Rabelais", en Revue des Langues Romanes, LXXX, 1932, Montpellier, págs. 129-138.

54 El mérito de haber puesto de relieve este ataque se debe a Gillet, en el artículo ya citado.

55 Quevedo, Obras Completas, Madrid, Aguilar, 1932, pág. 657.

56 Huesca, Pedro Blusón, Imprenta de la Universidad, Año 1629. 


\section{ANTONIO DOMINGUEZ}

mado FRANCISCO RABELES, amaneció para hacer noche del todo la poca luz de la fe. Era éste de ingenio picante, pronto, despeñado, inclinado a mal, y de lengua malediciente, licenciosa y donayrosa, que asi se llama ahora la mala lengua: habia pasado los primeros tercios de su vida por bodegones y casas de vicios, entre charlatanes y cacharreros, gente de mucha alma y poca conciencia, pues viven como tuvieran a ésta quienes lo reprehenda, y como si tuvieran de aquella para guardar y perder. Recogió menos curioso que libre, con deseo de hacer famoso su nombre y célebre su ingenio, un montón de cuentos, novelas, donayres, y rodeándolos a su modo, imprimió un libro concertado de desconciertos en que fisga y hace baldón y burla de los clérigos y religiosos, y de la honestidad de las monjas; a la traza que entre los italianos es Bocaccio aunque más humilde de estilo, más altivo y atrevido. Los libros de este RABELES, con otros de Juan Maroto, que compuso en verso pastoril, ayudaron al desprecio y desestima de la religión católica, fundada en el estado eclesiástico, y dispusieron con ánimos, para que a poco tiempo y a pocos lances se introduxera la común heregía, originada de este principio al aparecer liviano, que no lo es, porque de las personas eclesiásticas, y más religiosos no se ha de hablar en público, sino con gran reverencia",57.

A la par que primera crítica conocida emitida en España sobre Rabelais, este folleto es también un duro ataque que quiere desmontar los argumentos de Quevedo, que pasaba por ser el discípulo aventajado de Rabelais. La precisión con que Alíaga define algunos aspectos de la creación rabelesiana -aunque erróneamente-, el reconocimiento de su agudo espíritu, su aventurera existencia, el juicio que emite sobre la composición de sus novelas, su comparación con Bocaccio y las consideraciones sobre su estilo, nos permiten estimar que Rabelais, en el siglo XVII, era bien conocido en España, tanto como para que su obra fuese tan duramente atacada y acusada de herejía y, así, de paso, se desprestigiaba y desautorizaba a Quevedo.

¿Se había inspirado Quevedo en Rabelais? De acuerdo con el opúsculo citado cabría pensar que sí. Una lectura atenta de la obra de Quevedo, cuyo agudo y moradaz ingenio, además de sus chascarrillos y demás burlas mordaces y "groseras", parece evidenciar el conocimiento y amor con que Quevedo debió leer e inspirarse en la obra de Rabelais. La inspiración es evidente tras una lectura de su obra; y el hecho de que la leyó se comprueba cuando nuestro agudo y brillante caballero de Santiago, excelente ensayista político, pinta un breve cuadro del cardenal Richelieu ${ }^{58}$ :

"Cuando entendí que no había que hacer más en la memoria del eminentísimo, columbré dos librillos, uno mayor que otro, y un rótulo

58 Quevedo, Vista y anatomia de la cabeza del Cardenal Armando de Richelieu, en Obras Completas, pág. 543. 


\section{RABELAIS Y ESPAÑA}

encima, que decía: Biblioteca Armandina Ruchelana. El otro tenía por título: Obras de Marco Francisco Rabelés, doctor en medicina: contiene cinco libros de la vida, hechos y dichos heróicos de Gargantua y de su hijo Pantagruel. La Pronosticación de Pantagruel con el oráculo de la diosa Babuc. Y otros muchos tratados semejantes. Estaban muy bien encuadernados y tan llenos de registros, que entendí era el breviario de su eminencia" 59 .

Quevedo da cuenta de las obras de Rabelais y además se atreve a jugar en términos rabelesianos: cuando habla del breviario de su excelencia, está aludiendo a esos famosos libros colocados en los anaqueles entre mil y un registros diferentes: es decir, esos sabrosos frascos que aparentando ser libros contenían toda la gama de licores y sabores imaginables, dándonos así una imagen burlona del Cardenal.

\section{Rabelais hoy}

El afán de no exceder los límites que nos habíamos fijado en la elaboración de este trabajo nos hace no considerar en esta ocasión la impronta que Rabelais ejerció en la España de los siglos XVIII y XIX. Su fortuna, lejos de ser desdeñable, todavía no alcanzaba las cotas que un autor de su magnitud requerian.

En la actualidad comienza a ser conocido del gran público y son diversas las editoriales que han acometido la publicación de sus obras completas e incluso, en los últimos días de 1974 -cuando se acaba de redactar este trabajo- ha aparecido la traducción castellana de un magistral estudio sobre Rabelais ${ }^{60}$.

Esperanzados por los nuevos derroteros que pretenden sacar del ostracismo a nuestro autor en España, tememos, sin embargo, que de su todavía inexcusable actualidad únicamente quede esa imagen chusca y estereotipada, que el propio Cela ${ }^{61}$, ha contribuido a extender:

"Rabelais es un loro de mucho cuidado, un loro procaz y sin principios, un loro descastado del que no hay quien haga carrera. A lo mejor está una temporada algo más tranquilo, diciendo chocolate y Portugal y demás palabras propias de un loro fino, pero como es un inconsciente, cuando menos se espera y a lo mejor su dueña está con una visita de cumplido, se descuelga declamando oridinarieces y pecados con su voz cascada de solterona vieja. Angelito, que es un chico muy piadoso de la vecindad, estuvo tratando de llevar a Rabelais al buen camino, pero no consiguió nada; sus esfuerzos fueron en vano y su labor cayó en el vacío. Después se desanimó y lo fue dejando poco a poco, y Rabelais,

59 Ibid., pág. 543.

60 M. Bajtín. La cultura popular en la Edad Media y en el Renacimiento. El contexto de Rabelais. Barcelona, Barral editores, 1974.

61 Camilo José Cela, La Colmena, 1950, Alfaguara, 1.a ed. bolsillo, 1971, pág. 131. 


\section{ANTONIO DOMINGUEZ}

ya sin preceptor, pasó unos quince días en que sonrojaba oirle hablar. Cómo sería la cosa que hasta llamó la atención a su dueña un señor del principal, don Pío Navas Pérez, interventor de los ferrocarriles.

- Mire usted Señora, lo de su lorito ya pasa de castaño oscuro. Yo no pensaba decirla nada, pero la verdad es que ya no hay derecho. Piense usted que yo tengo una pollita en edad de merecer y que no está bien que oiga estas cosas ¡Vamos digo yo!

- Sí, don Pío, tiene usted más razón que un santo. Perdone usted, ya le llamaré yo la atención.

¡Este Rabelais es incorregible! 